Aletria, Belo Horizonte, v. 29, n. 3, p. 283-304, 2019

(c) (1)

\title{
Heranças da escrita desde a condição feminina: notas sobre pintura e literatura
}

\section{Women's Written Heritage: Notes on Painting and Literature}

\section{Luciana Abreu Jardim}

Universidade Federal do Pampa (Unipampa), Jaguarão, Rio Grande do Sul / Brasil lucianajardim.1@hotmail.com

Resumo: Na intenção de problematizar os efeitos do primado do falo em nossa cultura escrita, propõe-se um retorno a heranças soterradas pela hegemonia falocrática. Nesse sentido, a alternativa sugerida contra o rebaixamento da escrita produzida pelas mulheres encontra no pensamento de Julia Kristeva um caminho a ser percorrido pela teoria da literatura. A proposta sustenta-se no retorno a algumas referências pictóricas ocidentais que participam de diferentes obras dessa pensadora. No cruzamento da pintura e literatura, encontra-se em Polylogue a recuperação da leitura de Giotto por Matisse e reflexões acerca da cor. Em Possessões, nota-se que o debate se mantém a partir das reflexões em torno de Artemísia Gentileschi e de Georgia O'Keeffe. No volume Oódio e o perdão, as cartas o'keeffianas aprofundam a relação entre sua pintura e possíveis transformações sintáticas. Trata-se, portanto, de localizar, ao longo da obra de Kristeva, argumentos que produzam abertura a escritas por vir.

Palavras-chave: escrita; pintura; feminino; Julia Kristeva.

Abstract: In order to question the effects of the phallus primacy in our written culture, I propose a look back on the heritage that has been buried under phallocratic hegemony. In this respect the suggested alternative against the contempt for writing produced by women finds in Julia Kristeva's work a source to be regarded by Literature Theory. The proposal is based on returning to some Western pictorial references that are present in different works by this thinker. In the cross between painting and literature, we find in Polylogue the recovery of Matisse's reading of Giotto as well as reflections on color. In Possessions, the debate is supported by reflections about Artemisia Gentileschi and Georgia O'Keeffe. In Hatred and Forgiveness, the O'Keeffe letters deepen the 
relationship between her painting and possible syntactic transformations. This paper, therefore, seeks to locate, within Kristeva's work, arguments that may produce an opening to the writings to come.

Keywords: writing; painting; women; Julia Kristeva.

Há alguns caminhos, entre a vida e o texto, escolhas mediadas pela experiência sensível, quando se buscam sentidos na rebaixada condição feminina. Apesar de todos os movimentos e ondas do feminismo, ainda há muito a ser dito e escrito a respeito do pensamento produzido por mulheres. Assim, proponho pensar, a partir de Julia Kristeva e sua teoria linguística, a respeito da codependência das modalidades linguísticas do semiótico e do simbólico. Nessa perspectiva linguística, somos instigados a buscar, especialmente a partir da modalidade do semiótico, possíveis percursos alternativos ou simplesmente esquecidos da linguagem poética na sua relação com o processo criativo feminino. Essa modalidade compreende uma camada pré-sígnica, que participa da formação do sujeito falante, de modo a dar vazão a infrassignificados que podem retornar à linguagem, considerando a sua codependência com a modalidade linguística do simbólico. Pesquisas sobre o semiótico abrem um vasto campo de estudos, principalmente em teoria literária, para questões em torno do abalo do par opositivo pensar x sentir. Trata-se de entrar em contato com modos de sentir ainda pouco explorados pelos teóricos da literatura, viabilizando brechas interpretativas aos leitores para a (re)criação do texto, de modo a levar em consideração as sensações que atravessam os corpos e, em seguida, animam a linguagem propriamente dita. Pensar com Kristeva, essa autora que não se cansa de pensar e sentir lá onde muitos desistem porque preferem o conforto de suas especificidades, compreende assumir riscos, ampliar fronteiras do conhecimento, deixar-se contaminar pela imbricação de searas tão heterogêneas quanto relevantes, especialmente em seus cruzamentos por vir.

Não apenas os poetas de vanguarda, Lautréamont e Mallarmé, que ilustram a tese desenvolvida em $A$ revolução da linguagem poética, de 1974 - são evocados para fundamentar uma linguagem que destoa de teorias linguísticas alicerçadas sobre as limitações da gramática, como sinaliza a teoria chomskiana, mas também outros excluídos ganham a cena no modelo de linguagem proposto pela teórica, entre eles aqueles cuja linguagem excede as formas correntes do uso da língua. Tributário da herança psicanalítica, o modelo proposto por Kristeva se inspira no 
legado de Benveniste, que, em suas investigações linguísticas, reconheceu a importância das contribuições freudianas para a linguagem. Assim, também Kristeva busca nos caminhos da linguagem percorridos por Freud - os quais foram por ela retomados no volume Sentido e contrassenso da linguagem $^{1}$ (2000) - apontar uma via que, na esteira de Culioli ${ }^{2}$, leva em consideração o domínio das pulsões sobre a linguagem. Dessa forma, a psicanalista, e também teórica da literatura, além de incluir aqueles que, a despeito de limitações e/ou exclusões sociais e psiquiátricas, circulam como sujeitos falantes, também aponta o terreno pulsional daqueles que habitualmente já participam da linguagem, aproximando-nos, assim, pelas diferenças profundas que são revertidas tanto em respeito pelas singularidades quanto pelo compartilhamento agônico do corpo e sua (im)possibilidade de tradução na esfera do pensamento.

Se no âmbito estético os poetas de vanguarda são aqueles que mobilizam as pesquisas de Kristeva, a sugestão que se esboça aqui é a de buscar, na palavra escrita, formas para transgredir a lógica binária de visibilidade e de invisibilidade, promovidas pelo discurso fálico e suas ambições que gravitam ao redor de predicados cujas raízes remontam ao pensamento cristalizado em ideais esculpidos sob as formas de clareza, objetividade e finalidade, entre outros atributos que sempre escapam àqueles cuja escrita já se afasta de esquemas totalizantes.

Em um artigo de Polylogue, intitulado "A alegria de Giotto", de 1977, estão algumas pistas que me levam a reconhecer no interesse da teórica pela palavra pintada uma saída para o fardo que acompanha a escrita falocêntrica. A observação do pintor Matisse (daí percebemos como o pensamento dos pintores interfere nas questões teóricas dessa pensadora) ao lado da pintura de Giotto permite um retorno visual à modalidade linguística do semiótico, uma vez que Matisse encontra elementos que sustentam a tese de bases pulsionais adotada pela psicanalista, que se ligam à cor na pintura. Sensações se manifestam a partir do contato com o efeito cromático de suas telas - adquirindo dimensão sinestésica, de acordo com o fragmento que ela recorta do ensaio do pintor: "Só há, no

\footnotetext{
${ }^{1}$ Segundo o capítulo "Les Métamorphoses du 'language' dans la découverte freudienne (Les modèles freudiens du language)", de KRISTEVA. Sens et non-sens de la révolte, p. 51-102.

${ }^{2}$ Cf. "Falar em psicanálise: os símbolos da carne e do retorno" (KRISTEVA. Meu alfabeto: ensaios de literatura, cultura e psicanálise, p. 55).
} 
fim das contas, uma vibração tátil comparável ao 'vibrato' do violino e da voz"3. No artigo de Kristeva, há referências sobre as percepções da retina, as quais levam a uma perturbação do que seria, segundo o texto de Matisse, considerado no âmbito da sensação de "tranquilidade", das expectativas de superfície e também do que reconhecemos sob a designação do "contorno". Não se trata aqui de resgatar uma origem para o desenvolvimento do uso da cor na arte pictórica, mas a intenção é a de realçar mudanças oriundas de um momento artístico que se afasta das regras da perspectiva, perturbando a nossa relação espacial e afastandose de critérios já sedimentados de nossa percepção do mundo, a saber, a representação e a verossimilhança. Kristeva ilustra o seu artigo sobre Giotto com um detalhe do Julgamento final, da Capella degli Scrovegni, em Pádua. No entanto ${ }^{4}$, apesar de reconhecer a relevância do aspecto sociológico por trás de uma imagem cuja história apresenta elementos bíblicos, ela prefere se dedicar à análise do espaço e de sua relação com a cor. A autora observa, no entanto, que o caráter revolucionário atribuído à obra de Giotto se localiza antes no que se chama de "organização geométrica" do que na importância da cor ${ }^{5}$. Mesmo em estudos sobre pintura, Kristeva constata certo descaso quanto aos possíveis efeitos da cor. A teórica enaltece a liberdade que vem da cor, que permite um jogo inalcançável de formas e de figuras, sendo, por esse motivo, do "domínio do gosto" ". Não são as formas ou os desenhos dos afrescos de Giotto que ganham a cena de sua argumentação, mas sim o azul, capaz de perturbar os visitantes assim que entram na Capella degli Scrovegni. Seguindo o livro de Ruskin sobre Giotto (Giotto and his work in Padua, de 1854), Kristeva nos mostra que antes do pintor, no século XI e no início do século XII, dominava o palor, que acompanhava algumas cores, como o vermelho, o verde e o amarelo ${ }^{7}$. O azul de Giotto acrescentou outra renovação à cena visual: a luminosidade.

Como um desdobramento desse artigo, voltando-se ao campo da literatura, poderíamos buscar os textos literários que participam

\footnotetext{
3 “'Il n'y a, en fin de compte, qu'une animation tactile comparable au 'vibrato' du violon et de la voix" (MATISSE apud KRISTEVA. La Joie de Giotto, p. 392, tradução minha).

${ }^{4}$ KRISTEVA. La Joie de Giotto, p. 384.

${ }^{5}$ KRISTEVA. La Joie de Giotto, p. 389.

${ }^{6}$ KRISTEVA. La Joie de Giotto, p. 394.

${ }^{7}$ KRISTEVA. La Joie de Giotto, p. 399.
} 
dessas mudanças e, a partir delas, reconhecer características que levam à dissolução de formas instituídas da escrita, pesquisando as alterações sintáticas e formas narrativas, por exemplo.

Nessa perspectiva, a relação entre pintura e escrita volta à cena das pesquisas de Kristeva em recente artigo, no último volume de sua trilogia dedicada aos "poderes e limites da psicanálise". No artigo "Des madones aux nus: une représentation de la beauté féminine", alguns pintores são relacionados a expoentes literários, com a finalidade de não apenas aproximar narrativas com imagens, mas sobretudo de chamar a atenção para as marcas do masculino que fundam o imaginário feminino ${ }^{8}$. Assim, a Beatriz de Dante pode ser acompanhada das imagens de Giotto. Proust pode ser lido à luz dos pintores impressionistas. Escritores que carregaram o traço no experimentalismo, como James Joyce e Georges Bataille, foram contemporâneos de Picasso, o que confirma o espírito de uma época em suas transformações profundas. Em contrapartida, percebe-se que, na escrita e na pintura, o gosto, a despeito de suas rupturas e vanguardismo, vem da primazia do masculino.

Um caminho para o abalo da escrita marcada pelo falocentrismo pode estar no cuidado da cor, que, desde o ensaio sobre Giotto, de 1977, sinaliza para o que é designado de aspecto revolucionário da cor ${ }^{9}$. No entanto, os exemplos que ilustram a tese, todos notáveis pintores, não incluem mulheres. Entre eles estão Cézanne, Matisse, Rothko, Mondrian. Apesar dessa constante, é a partir da faculdade do gosto, no artigo sobre Giotto, sendo associado ao que chama de "capricho", que a revolução da cor é mencionada para, mais adiante, ser retomada, sem, no entanto, pertencer a uma genealogia, de modo a eclodir em imagens pintadas por uma mulher.

Curiosamente, a referência à pintura feminina se manifesta num romance do gênero policial. Antes de apresentá-la, gostaria de me deslocar para outra pesquisa da mesma autora, que trata do mesmo assunto, ainda sem problematizar a relevância da pintora sobre a qual dedico a herança revolucionária de possíveis caminhos contra uma estrutura de escrita que se pretende totalizante.

A investigação pictórica na obra de Kristeva se adensa com a publicação de Visões capitais (1998) - experiência-escrita resultado de

\footnotetext{
${ }^{8}$ KRISTEVA. Des madones aux nus: une représentation de la beauté féminine, p. 149. ${ }^{9}$ KRISTEVA. La Joie de Giotto, p. 394.
} 
suas visitas ao Louvre, cuja publicação é posterior ao romance policial. Das páginas ilustradas com telas tão distintas como as de Giambattista Tiepolo, Andrea Solario, Paul Klee e Andy Warhol, para exemplificar alguns dos diferentes tempos e estilos por ela percorridos, passa uma sutil linha de sutura, cuja reflexão conceitual se manifesta especialmente no segundo volume de suas aulas dedicadas ao cruzamento de áreas do conhecimento como psicanálise e teoria da literatura. Em $A$ revolta íntima (1997) Kristeva propõe refletir sobre o íntimo como sendo a nossa experiência "mais interior". Note-se que algo dos fantasmas arcaicos freudianos atravessa uma busca interior, mas, obviamente, não se deve reduzir a essa inspeção cuja herança, é preciso não ignorar, não escapa ao legado psicanalítico ${ }^{10}$. As pinturas selecionadas para compor as "visões capitais", cujo enfoque recai sobre uma cabeça que flutua sem o restante do corpo, ilustram um dos fantasmas arcaicos a respeito do qual a teórica dedica não apenas um livro de ensaios, mas também um romance policial. Antes de chegar a esse romance, preciso fazer justiça a uma referência pictórica feminina - Artemísia Gentileschi.

Essa pintora, que frequentou o mesmo tempo do célebre Caravaggio, tem seu autorretrato numa das páginas dessas visões capitais. No fecho do ensaio "Degolações", que abre com ilustrações dos traços de Lucas Cambiaso e de Martin van Heemskerck, além de outras notáveis cabeças cortadas que foram retratadas por pintores, incluindo, obviamente um detalhe de "Davi e Golias", de Caravaggio, está o autorretrato de Artemísia Gentileschi. Há de se pensar sobre o fecho de um ensaio que apresenta o autorretrato de uma mulher, depois de uma série de degolações, inclusive uma retratada pela própria Artemísia, na qual Kristeva tece comentários sobre a tela "Judite e Holofernes", reconhecendo traços da violação bíblica que participam também da vida da pintora, e que, no entanto, não são o mais relevante de sua trajetória, de modo a reverter a violência em expressão artística. Para Kristeva, essa tela, que ela chama de "obra feminina" desempenha um duplo papel, a saber, o de "combater o poder fálico do homem violador" e também de criticar o que reconhece por "passividade" da vítima".

Diante de uma mulher pintora cujo braço, em atividade de pintura, esconde o desenho por vir, gesto do corpo que poderia muito

\footnotetext{
${ }^{10}$ KRISTEVA. La Joie de Giotto, p. 80.

${ }^{11}$ KRISTEVA. Décollations, p. 85.
} 
bem acompanhar a noção de "enceguecimento", proposta por Jacques Derrida em Pensar em não ver ${ }^{12}$, o debate não se restringe aos traços do feminino; ele antes se amplia para o flagrante de invisibilidades que cegam pelo excesso de luminosidade. Não é à toa que Derrida liga o efeito de enceguecimento a grandes escritores que perderam ou quase perderam a visão.

Em Possessões, de 1996, curiosamente publicado apenas dois anos antes de Visões capitais, nota-se que o objeto de estudo da psicanalista e romancista do gênero que ela reconhece sob a designação de polar metafísico gravita em torno de uma cabeça cortada. Neste, Gloria Harrison, protagonista tão ausente-presente quanto Brás Cubas, ainda que não seja a personagem-narradora do romance, abre a narrativa a partir de um corpo marcado por descrições mediadas pelo tom de horror que podem ser retomadas teoricamente através da abjeção - noção desenvolvida por Kristeva no ensaio Poderes do horror. O cadáver de Gloria Harrison, impactante porque já não participa de nossa vida, ilustra uma das zonas de indeterminação indicadas por Kristeva nessa obra - e, possivelmente pela sua irreversibilidade, resida na imagem desse cadáver a manifestação mais expressiva do horror. $\mathrm{O}$ corpo morto, emblemático no relato bíblico, como é retomado pela teórica no Levítico (11:20-40) através da relação de pureza e impureza entre vivos x mortos, reaparece nesse polar para nos assombrar com a imagem abjeta despertada pelo corpo dos animais mortos. O cadáver simboliza, portanto, uma zona de indeterminação, já não se pode mais falar em corpo, mas antes no que chama de "não corpo", também já não há mais o lado espiritual, a alma e sua ligação com a "palavra de Deus"13. A construção da romancista atualiza a insuportável sensação de mal-estar diante de uma experiência de não pertencimento, circundada, no entanto, por índices tão sofisticados quanto perecíveis. O relógio Cartier, o anel de diamante, as unhas manicuradas, as pernas bronzeadas, os escarpins, coleção de índices de um sujeito recém-saído de uma vida em suas demandas de status econômico-sociais, acessórios de um ex corpo-vivo, acentuam essa retirada abrupta e cruel do mundo dos vivos. Estamos diante de uma descrição de um assassinato, no caso,

${ }^{12}$ DERRIDA. Com o desígnio, o desenho, p. 172.

${ }^{13}$ KRISTEVA. Pouvoirs de l'horreur. Essais sur l'abjection, p.127. 
de uma degolação: “[...] não havia dúvida, era mesmo Gloria, não faltava nada, exceto a cabeça"14.

Esse fantasma arcaico da castração, transformado em cena de filme policial, revisto sob o gênero romance, ainda que sob uma capa popular, põe em cena uma mulher - mas não apenas uma mulher morta, sem cabeça: a protagonista assassinada trabalhava como tradutora, uma mulher dedicada à palavra escrita. Esse fantasma, que pode ser lido como a (im)possibilidade histórica da legitimação do pensamento feminino, desloca-se para outras expressões das atividades que, ao longo dos séculos, têm ocupado a vida de uma mulher. Na fictícia cidade de Santa Bárbara, Gloria Harrison atua como tradutora de Shakespeare e de Philip Roth. No entanto, esse trânsito na cultura escrita não facilita a comunicação dela com o filho autista, que, curiosamente, se expressa através de desenhos, reproduzindo telas de pintores. Dessa questão de linguagem e suas margens para discutir o autismo, Possessões se desloca para um tema que dará luzes para repensarmos o rebaixamento da condição feminina na cultura. O polar é atravessado por diversas referências pictóricas ${ }^{15}$, além de reflexões filosóficas cuja densidade entrelaça temas que podem ser localizados em pesquisas do romancista - como a questão do estrangeiro e, recentemente, o enfoque sobre a maternidade.

Recai sobre essa mãe morta, assassinada, degolada, a ser retratada desde a abertura do livro como uma morta-viva numa rede de contrassensos e vilanias que ultrapassam a cidade fictícia de Santa Bárbara, tornando visíveis as crueldades do mundo globalizado e, ao mesmo tempo, permitindo um retorno pictórico para a violência, sobretudo aquela ligada à condição feminina e a sua amiúde frustrada inserção intelectual, uma decepção a remontar outros séculos. Possessões não é indiferente à violência sofrida pela pintora Artemísia, tampouco a sua resposta artística, em sua versão da degolação de Holofernes, de acordo com a sua narradora. Esse romance policial metafísico, para além

\footnotetext{
${ }^{14}$ KRISTEVA. Possessões, p. 11. No original: “[...] aucun doute, c'était bien Gloria, rien n'y manquait, sauf la tête" (KRISTEVA. Possessions, p. 11).

${ }^{15}$ No capítulo "O corpo atravessado pela técnica", da tese Clarice Lispector e Julia Kristeva: dois discursos sobre o corpo, retomo algumas referências pictóricas que, inicialmente, pavimentaram o caminho para pesquisas subsequentes sobre a relação pintura-literatura (cf. JARDIM. Clarice Lispector e Julia Kristeva: Dois discursos sobre o corpo, p. 218-397).
} 
de uma diegese voltada à descoberta do assassino de sua protagonista, recupera também uma genealogia perdida acerca da violência feminina. O romance põe em cena a violência que eclode a partir do esquecimento e do descaso do legado criativo das mulheres. A morte de Gloria Harrison representa claramente a tentativa de apagamento de arquivos literários. $\mathrm{O}$ assassinato da tradutora interrompe, em parte, o fluxo de possíveis trocas de outras histórias, outros espaços, a abertura para a língua do outro. Artemísia, cuja vida-obra se modelou em virtude de um tempo hostil à criatividade feminina, entra, de forma oblíqua no enredo e, ao lado de Gloria Harrison, para dar eco às sucessivas tentativas de apagamento que uma mulher pode sofrer quando ambiciona deixar rastros: "O importante é que pintou como nenhuma outra mulher o fez antes ou depois dela, e que não pintou qualquer coisa, mas de fato um homem estuprado, ou melhor: decapitado pela própria mão dela, da genial Artemísia! ${ }^{16 "}$. Mary Garrard $^{17}$, mesmo reconhecendo a influência da técnica de Caravaggio sobre a pintura de Artemísia, não deixa de narrar as diferenças entre as formas de pintar de ambos. No estilo da pintora, há sobretudo força física na composição de Judite e também na serva, que a acompanha na degolação de Holofernes, ao passo que na retração de Caravaggio sobressaem a fragilidade de Judite e algo que margeia a passividade e a falta de vigor, acentuada pela falta de energia que ele retrata a velhice da serva, conforme a sugestão gestual de sua amargura a segurar um tecido enquanto a outra age. Vejamos como o episódio da violação de Artemísia reverte-se em celebração de pincéis pela narradora de Possessões, refletindo considerações semelhantes às que foram expostas, sob o gênero ensaio, em Visões Capitais $^{18}$ :

Não houve sequer uma feminista da belle époque que não tenha esquadrinhado os detalhes da carnificina, para aplaudir os talentos de Artemísia e a proeza de Judite. Sem esquecer o escândalo que foi, ao que parece, no início

\footnotetext{
${ }^{16}$ KRISTEVA. Possessões, p 131. No original: “L'important est qu'elle peignit comme nulle autre femme ne le fit avant ou après elle, et qu'elle ne peignit pas n'importe quoi, mais bel et bien un homme violé, mieux: décapité par sa propre main à elle, la géniale Artemisia!" (KRISTEVA. Possessions, p. 155).

${ }^{17}$ GARRARD. Artemisia Gentileschi: The Image of the Female Hero in Italian Baroque Art, p.290.

${ }^{18}$ KRISTEVA. Décollations, p.85.
} 
do século XVII, o estupro da mesma Artemísia por um pintor do ateliê paterno, um certo Orazio que, denunciado bem tarde pelo pai da estuprada, foi levado à justiça antes que os amantes se reconciliassem, parece, bastante misteriosamente, no rastro do processo. Caso duvidoso, este: mestre e discípulo, pai e filha, estuprador e estuprada, quem estupra quem? AArtemísia foi uma puta, um joguete ou um gênio? Provavelmente tudo isso ao mesmo tempo, que importa? ${ }^{19}$.

Não importa, de fato, porque o tempo fez a sua reparação, transformando a arte de Artemísia em uma referência na pintura e, apesar da contribuição inestimável do traço dessa pintora corajosa, ainda continuamos sem o devido reconhecimento e abertura para o tão almejado reconhecimento da criatividade feminina e inserção efetiva de suas formas pensadas em instituições. Kristeva deixa ecoando as descrições da tela de Artemísia ao lado de um episódio do sonho da detetive Stéphanie Delacour. E não é somente o assassinato de Gloria Harrison que está em jogo nesse romance, mas, ao lado desse crime e para melhor compreendêlo, também nos invade, principalmente se somos parte ou empáticos ao universo feminino, a vida fantasmal sistematicamente rebaixada e soterrada das mulheres:

O sonho de Stéphanie e o quadro de Artemísia: imagens virtuais que se contaminam. Duas mulheres atacam o corpo deitado do general assírio: a serva de rosto blasé e uma Judite feroz, flutuando em seu vestido de brocado. Um suave veludo carmesim envolve as coxas afastadas do homem, contraponto do embate confuso de seis braços que, na altura da cabeça, perpetram o que parece um interminável estupro. Com todo o seu peso, a serva

${ }^{19}$ KRISTEVA. Possessões, p. 130-131. No original: "Pas une féministe de la Belle Époque qui n'ait scruté les détails du carnage pour applaudir aux talents d'Artemisia et à l'exploit de Judith. Sans oublier le scandale que fut, paraît-il, au début du XVIIe. siècle, le viol de la même Artemisia par un peintre de l'atelier paternel, un dénommé Orazio qui, dénoncé bien tard par le père de la violée, fut traîné en justice avant que les amants ne se réconcilient, semble-t-il, assez mystérieusement, dans la foulée du procès. Affaire douteuse s'il en fut: maître et disciple, père et fille, violeur et violée, qui viole qui? Artemisia fut-elle une putain, une jouet ou une génie? Sans doute toute cela à la fois, quelle importance?" (KRISTEVA. Possessions, p. 155). 
imobiliza a vítima, enquanto um violento movimento leva Judite à margem direita do quadro: com a mão direita, a soberana mergulha uma espada na garganta ofertada, $\mathrm{e}$ com a mão esquerda prega na cama a cabeça do macho. Nenhum horror nos traços da assassina. Só a rígida contenção de seu corpo, afastando-se do sangue que jorra, trai alguma repulsa. Em compensação, o rosto exige a concentração de uma matemática, ou bióloga, ou cirurgiã que, no esforço, já saboreia a vitória. A do saber absoluto? Do povo de Israel? Da mulher sobre o homem? ${ }^{20}$

O que continua a nos surpreender em Artemísia se insinua no caminho aberto a outras pintoras, ou, de forma mais ampla, no que se deixa fazer com um traço e a liberdade de escolher a sua própria herança.

$\mathrm{Na}$ sugestão de genealogia imagética do feminino que se esboça entre Possessões e Visões capitais, apesar da distância e até das diferenças entre os estilos, desenha-se a mesma intenção a romper com o instituído na pintura a partir de Georgia O'Keeffe. Por que O'Keeffe? Em Possessões, essa pintora se manifesta para, inicialmente, acompanhar, ao lado de Artemísia, o descaso que pode sofrer a trajetória feminina. No entanto, surge na ilustração do jogo corporal dessa personagem, que se narra muito confortável na sua sexualidade e na troca erótica com os homens, uma cena na qual a alusão às flores o'keeffianas explora um giro na "revolução da cor", seguindo o gérmen dessa revolução, outrora exposto no ensaio sobre Giotto:

${ }^{20}$ KRISTEVA. Possessões, p. 130. No original: "Le rêve de Stéphanie et le tableau d'Artemisia: des images virtuelles qui se contaminent. Deux femmes s'acharnent sur le corps couché du général assyrien: la servante au visage blasé et une Judith farouche, flottant dans sa robe de brocart. Un suave velours cramoisi enveloppe les cuisses écartées de l'homme, contrepoint de l'empoignade confuse de leurs six bras qui, côté tête, perpètrent comme un interminable viol. De tout son poids, la servante immobilise la victime tandis qu'un violent mouvement emporte Judith à la marge droite du tableau: de sa main droite, la souveraine plonge une épée dans la gorge offerte, de sa main gauche elle clue au lit la tête mâle. Nulle horreur dans les traits de la meurtrière. Seule la rigide réserve de son corps, s'écartant du sang qui gicle, trahit quelque dégoût. Sa face, en revanche, dépeint la concentration d'une mathématicienne ou d'une biologiste ou d'une chirurgienne qui, dans l'effort, savoure déjà sa victoire. Celle du savoir absolu? Du peuple d'Israël? De la femme sur l'homme?" (KRISTEVA. Possessions, p. 154-155). 
Não, o sexo jamais fora estupro para Stéphanie, não importa o que pudessem pretender suas amigas feministas em nome da humanidade, ou antes, em nome da feminilidade; fora mesmo nisso que tivera de se separar delas. Estupro, nunca. [...] Flores oferecidas ao céu sob o pincel de Georgia O’Keeffe. Fragrâncias tornadas táteis nas páginas de Colette. Stéphanie sabia reconhecer nas obras dos outros aquele prazer sem nome que os homens lhe davam. E que ela gostava de preservar, velado, insular ${ }^{21}$

O estilo o'keeffiano se forjou já na cor que faz esmaecer os contornos em pinceladas florais a abalar a estrutura binária visível $\mathrm{x}$ invisível. A intenção de totalidade da imagem se perde no excesso das dimensões dos objetos pintados ou esboçados, sugestões que nos fazem deslizar pelos detalhes gestuais dessa pintora coreógrafa - e essa cor em movimento que ela deixa vir nos mobiliza, impressiona antes mesmo de uma busca pelo sentido. Ao invés de buscar o todo para formar a imagem, rompe-se com a intenção de representação - o olhar se desloca para a contemplação de nuances - a exemplo do que somos levados a fazer diante de uma tela de Rothko. Seguindo, no entanto, o recente ensaio de Kristeva "La forme inévitable", do volume La haine et le pardon, nos surpreendemos inicialmente com um fragmento de uma carta o'keeffiana no qual a pintora menciona a necessidade de retratar uma "forma" 22 , o que parece destoar de seu traço a incitar mobilidade contra a intenção de forma e sua possível sugestão de fixidez. Há, no entanto, a busca por uma forma que ela chama de "realmente viva", sendo caracterizada como

[...] o resultado natural dos esforços de um indivíduo para criar essa coisa viva a partir daquilo que seu espírito, se aventurando no desconhecido, experimentou, sentiu - sem

\footnotetext{
${ }^{21}$ KRISTEVA. Possessions, p. 131. No original: “Non, le sexe n'avait jamais été du viol pour Stéphanie, quoi qu'eussent pu prétendre ses amies féministes au nom de l'humanité, ou plutôt au nom de la féminité; c'est même là-dessus qu'elle avait dû se séparer d'elles. Jamais de viol. [...] Fleurs offertes au ciel sous le pinceau de Georgia O'Keeffe. Fragrances devenues tactiles dans les pages de Colette. Stéphanie savait reconnaître dans les oeuvres des autres ce plaisir sans nom que lui donnaient, à elle, les hommes. Et qu'elle aimait préserver, voilé, insulaire" (KRISTEVA. Possessions, p. 156). ${ }^{22}$ KRISTEVA. La Forme inévitable, p. 486.
} 
compreendê-lo -, e dessa experiência nasce o desejo de revelar esse desconhecido. ${ }^{23}$

Na sequência, O'Keeffe explica o seu processo de criação, que, por vezes, se revela consciente e, em outras, é totalmente desconhecido, ilustrando os mistérios do que não pode ser compreendido com a imagem cromática de um negro absoluto (le noir absolu). Apesar da opacidade, a pintora reconhece que se trata de um "trabalho que deve ser feito" 24 .

$\mathrm{E}$, antes desse recorte epistolar, Kristeva nos leva a refletir a respeito dos limites de qualquer artista e sua relação com a obra. Poderíamos afirmar que a obra está toda na tela, por exemplo? Ou haveria algo que resta nos movimentos íntimos da própria vida do artista? No caso de O'Keeffe, a obra, que se mistura à vida dessa pintora, se mescla à história de vida da pintora, contribuindo para a sua compreensão. Da vida de O'Keeffe, Kristeva captura a relação com o marido fotógrafo, mas parece se deter especialmente, ao comentar as fotos da pintora, na gestualidade de suas mãos, que são cristalizadas pelas lentes de Stieglitz, espécie de ousadia de movimento manual de uma mulher disposta a criar - atitude que não deveria escapar à atenção feminina. $\mathrm{Na}$ busca dos elementos semiotizáveis, nessas cartas e também em comentários esparsos e poéticos da ensaísta, a vida que capta os infrassignificados, misturando-se às cores que assinam o estilo o'keeffiano, passa por "sensações" e "respirações" e pela luta da pintora com as palavras, especialmente as palavras escritas nessas cartas.

Aquilo que pode ser resumido apenas como "desdém pela palavra" 25 , já que se trata de uma artista pintora, se encontra com o cuidado da cor, recuperado por Kristeva em outro fragmento de carta da pintora:

A cor é uma das grandes coisas desse mundo que faz com que a vida valha a pena ser vivida, e desde que eu comecei

23 “[...] le résultat naturel des efforts d'un individu pour créer cette chose vivante à partir de ce que son esprit, s'aventurant dans l'inconnu, a expérimenté, ressenti - sans le comprendre - et de cette expérience naît le désir de révéler cet inconnu" (O'KEEFE apud KRISTEVA. La Forme inévitable, p. 486, tradução minha. Carta de 1923).

${ }^{24}$ KRISTEVA. La Forme inévitable, p. 486.

${ }^{25}$ KRISTEVA. La Forme inévitable, p. 485. 
a pensar em pintura, me esforço a criar com os tubos de cor um equivalente para o mundo - a vida como eu a vejo. ${ }^{26}$

Nesse modo de ver o mundo, somos atropelados pelos detalhes, minúcias de dobras, arranjos plissados, efeitos produzidos por uma coreografia um tanto barroca entre mãos hábeis, elementos que desencadeiam algo do segredo do enceguecimento derridiano, através dos gestos e de pincéis que levam à própria visibilidade cegante, e também somos atravessados pela curiosidade de como seria a escrita dessa mulher. Kristeva não deixa de analisar a relação tensa da pintora com as palavras, chamando-a de uma "linguagem manipulada como uma matéria plástica" ${ }^{27}$. Inusitada essa designação, mas Kristeva explica, seguindo a análise das cartas, que a pintora mudava os pontos por serpentinas e, no processo de impressão, elas eram substituídas por travessões. Sensível à sintaxe o'keeffiana, a teórica se fixa na incompletude de suas construções frasais, que prefere chamar de "transformações" sintáticas, as quais são acompanhadas de frases muitas vezes "brutas" ou "ambíguas", uma vez que a artista estava imersa na vida, essa "matéria vivida" - e não me canso de voltar às palavras escolhidas pela teórica para analisar fragmentos da herança textual da pintora. Ao lado dos efeitos semiotizáveis da teoria da linguagem de Kristeva, estão as referências ao uso o'keeffiano das cores, de acordo com a descrição da sintaxe da pintora, que é sustentada pela teórica através dos ritmos vindos da matéria vivida pela pintora: "intensidades sobre uma superfície ou num volume". Uma escrita que acompanha os ritmos do corpo de uma pintora que optou por viver no deserto $^{28}$, conectando-se com as rochas, os crânios de vaca, as ossaturas delicadas e a luminosidade crestante do Novo México.

Como um caminho esperado, Kristeva também traça relações entre a pintura de O'Keeffe com literatura. Essa necessidade do encontro com o deserto, por meio de elementos daquela natureza que a teórica reconhece como uma experiência de "comunhão íntima", sobretudo

\footnotetext{
26 "La couleur est l'une des grandes choses de ce monde fait que la vie vaut pour moi la peine d'être vécue, et depuis que j'ai comencé à penser à la peinture, je m'efforce de créer avec les tubes de couleur un équivalent pour le monde - la vie telle que je la vois" (O’KEEFE apud KRISTEVA. La Forme inévitable, p. 494, tradução minha).

${ }^{27}$ KRISTEVA. La Forme inévitable, p. 491.

${ }^{28}$ Cf. BENKE. Georgia O'Keeffe (1887-1986): flores en el desierto, cap. 4: Visiones del desierto, p. 55.
} 
com os elementos que, na minha leitura, reenviam às telas de $\mathrm{O}^{\prime} \mathrm{Keeffe}$, como as flores, montanhas, os ventos e as cores, levam à poesia intimista de Emily Dickinson. Sem as palavras da poeta, O'Keeffe, no entanto, partilha do mesmo mundo sensível dessa poeta, cujas formas "florais", "siderais" e "coloridas" ${ }^{29}$ reenviam a muitas telas de nossa pintora intensa e introspectiva. Há também a ligação tecida com o poeta Francis Ponge, especialmente em "L'huître" ou "Le savon". Para Kristeva, os dois se encontram no uso das "intensidades cromáticas", o que se soma à intenção poética de uma palavra-objeto ${ }^{30}$.

A filosofia de Merleau-Ponty, sensível tanto ao conceito corpo quanto à análise pictórica, sobretudo em sua pesquisa desenvolvida em $O$ olho e o espírito, enriquece o pensamento de Kristeva. Em La révolte intime, a teórica, que busca recorrentemente tecer seus argumentos a partir de aproximações filosóficas e psicanalíticas, situa Merleau-Ponty como referência fenomenológica, ao lado de Sartre, para dar sustentação à importância da negatividade na história de nosso pensamento ${ }^{31}$. Decorre dessa contribuição, a consolidação do conceito de inconsciente na teoria psicanalítica e, por extensão, na teoria da linguagem por ela adotada, cuja herança é sobretudo freudiana. Nesse contexto, a teórica também observa nos estudos de Lacan a recuperação do legado fenomenológico não apenas de Husserl ou de Heidegger, cruciais para essa corrente filosófica, mas também o de Sartre e o de Merleau-Ponty e suas implicações linguísticas, que levam em conta os desdobramentos da faculdade da imaginação e suas (in)visibilidades. Na esteira da tensão entre o ver o ser visto, reflexões sobre a pintura e a literatura, portanto, não escapam a um retorno ao pensamento de Merleau-Ponty. Considerando as especificidades das atividades da escrita e da pintura, o filósofo, no ensaio "A linguagem indireta e as vozes do silêncio", procura aproximá-las, reconhecendo, por exemplo, a formação do significado no espaçamento entre os vocábulos, na função do escritor e a recepção distanciada do uso das cores e das linhas, no ofício do pintor ${ }^{32}$. Observase que, semelhante à modalidade linguística do semiótico, atravessada pelas virtualidades da experiência sensível, o pensador, por sua vez, em

\footnotetext{
${ }^{29}$ KRISTEVA. La Forme inévitable, p. 485

${ }^{30}$ KRISTEVA. La Forme inévitable, p. 496.

${ }^{31}$ KRISTEVA. La Révolte intime: pouvoirs et limites da psychanalyse II, p. 195-196.

${ }^{32}$ MERLEAU-PONTY. A linguagem indireta e as vozes do silêncio, p.163.
} 
sua proposta teórico-poética também inserida nos estudos linguísticos, sugere o que chama de uma "linguagem à segunda potência", servindo-se da imagem das cores para ilustrá-la: "E se houver, oculta na linguagem empírica, uma linguagem à segunda potência, onde de novo os signos levem a vida vaga das cores e as significações não independam de todo do comércio dos signos?".

Ao lado da possibilidade de diálogo com essas correntes de pensamento, de modo a incluir a experiência sensível, outro movimento se impõe em futuras pesquisas sobre a relação pintura e literatura, com a finalidade de trazer à cena o corpo e a abertura para a experiência mediada pelos sentidos. Trata-se de, inicialmente, dar espaço ao termo carne, seguindo os argumentos expostos pelo fenomenólogo em sua Fenomenologia da percepção, obra de referência para Kristeva. No ensaio "Falar em psicanálise: os símbolos da carne e do retorno", Kristeva sintetiza alguns sentidos desse termo, passando pelo vínculo com as sensações, de acordo com Sexto Empírico ${ }^{33}$, em Contra os eruditos e também pela relação entre desejo e corpo, conforme Platão, no diálogo Fédon. Sem esquecer do Novo Testamento, a autora elenca as acepções da carne que deixam em evidência a fragilidade do termo, mencionando o seu vínculo com o "corpo doente", a "fraqueza" e a "sujeira". Essa breve investigação acerca da carne, no estilo dos retornos do pensamento de Kristeva (que podem ser lidos como (re)voltas) alcançam, na atualidade, a herança de Merleau-Ponty no cruzamento com o que a teórica chama de "olhar psicanalítico". Assim, o termo carne é por ela atualizado como "um 'quiasma' entre o eu e o mundo" ${ }^{34}$. Nesse contexto filosófico-psicanalítico da carnalidade, deveríamos retomar, a partir das próprias referências da teórica sobre a relação corpo-linguagem, os questionamentos propostos pelas pesquisas de Melanie Klein. No segundo volume do gênio feminino, dedicado à vida e obra da psicanalista, Kristeva chama a atenção para o interesse das mulheres psicanalistas pelo arcaico e pelo orgânico ${ }^{35}$. Nessa perspectiva, a ligação arcaica com a mãe se evidencia, especialmente na teoria kleiniana, o que permite um deslocamento do primado da visão, amplamente sustentado na atualidade pelas ideias de Lacan, para a inclusão de experiências pautadas pela oralidade. Estamos, portanto,

\footnotetext{
${ }^{33}$ KRISTEVA. Falar em psicanálise: os símbolos da carne e do retorno, p. 54.

${ }^{34}$ KRISTEVA. Falar em psicanálise: os símbolos da carne e do retorno, p. 56.

${ }^{35}$ KRISTEVA. Le Génie féminin: la vie, la folie, les mots, tome II, p. 245.
} 
chamando à cena a tensão entre os desdobramentos dos sentidos da visão e do gosto. Sabe-se que as reflexões em torno da pintura têm como parâmetro o inestimável legado das pesquisas de Merleau-Ponty, as quais foram relidas por Lacan, e contribuíram para a disseminação do sentido da visão ${ }^{36}$. Kristeva volta ao XVI Congresso da Associação Internacional de Psicanálise, realizado no ano de 1949, momento em que se consolida o sentido da visão nos estudos lacanianos, através da apresentação de "Le stade du miroir comme formateur de la fonction du Je". Nessa ocasião, em virtude do destaque dado à visão em detrimento dos outros sentidos, a teórica faz questão de apontar para o "descompasso" estabelecido entre as pesquisas de Lacan e Klein ${ }^{37}$.

A despeito dessa hierarquia dos sentidos modelada pela trajetória de formação do pensamento filosófico, não podemos cair na simplificação do olhar. E Merleau-Ponty, em O olho e o espírito, foge da representação e de um olhar que estaria no âmbito de um contato físico-óptico com as coisas do mundo ${ }^{38}$. Para escapar da metafísica da presença, a definição de visão, segundo o filósofo, passa pelo diferimento da ausência do si mesmo. No entanto, resta algo a pensar a partir de um sentido que se torna o protagonista dos embates entre a carne e o espírito. Algumas pistas para o abalo do primado da visão estão nas metáforas pictóricas tecidas pelo pensador, curiosamente em torno da maternidade e do nascimento, que fazem renascer não apenas as ideias kleinianas sobre a oralidade, como também os arquivos de pensamento daquelas cujo gosto, considerando as acepções do termo, tem sido continuamente deixado à margem de nossa herança descoberta e legitimada. É preciso retornar ao que se aproxima do nascimento, em $O$ olho e o espirito, e se demorar, por exemplo, no que diz André Marchand - "Pinto talvez para surgir"39". E depois, é preciso

\footnotetext{
${ }^{36}$ Nesse sentido, a pesquisa de Charles Charles Shepherdson nos explica que o interesse de Lacan pelo pensamento de Merleau-Ponty emerge de uma busca técnica, voltada à investigação da pulsão na teoria psicanalítica. A despeito das divergências elencadas pelo autor entre o jogo de (in)visibilidades que atravessam as teorias de Merleau-Ponty e de Lacan, subsiste, no diálogo que o psicanalista busca com o texto de Merleau-Ponty, o privilégio do sentido da visão sobre os demais sentidos (SHEPHERDSON. Uma libra de carne: a leitura lacaniana d'O visivel e o invisivel, p. 98).

${ }^{37}$ KRISTEVA. Le Génie féminin: la vie, la folie, les mots, tome II, p. 366.

${ }^{38}$ MERLEAU-PONTY. L'Oeil et l'esprit, p.31.

39 "Je peins peut-être pour surgir" (MARCHAND apud MERLEAU-PONTY. L'Oeil et l'esprit, p. 31, tradução minha).
} 
continuar no fluxo das reflexões do filósofo, que segue pelo caminho da maternidade e, em alguma medida, faz estremecer o primado da visão a partir do "corpo materno": "A visão do pintor é um nascimento continuado ${ }^{40 "}$ ". Assim, o "entrelaçamento de visão e movimento" ${ }^{41}$, que dá à pintura a sua carnalidade, poderá alargar-se também para o gosto, deixando trançar o gesto com um sentido menos espiritual, mas talvez mais próximo das transubstanciações, que participam da gestualidade indicada pelo filósofo ${ }^{42}$.

Obviamente, essas aproximações constituem apenas referências breves que requerem estudos por vir das possíveis relações entre literatura e pintura desde, por exemplo, a forma artística de O'Keeffe. Gostaria de incluir, no entanto, seguindo o flagrante da "matéria vivida", conforme a recuperação do fragmento epistolar de O'Keeffe, duas autoras tão significativas quanto necessárias para o acompanhamento do trabalho de linguagem realizado por O'Keeffe. A primeira delas já foi citada num dos recortes que escolhemos de Possessões. Trata-se da escritora Sidonie Colette, que participa também do terceiro volume dedicado ao gênio feminino, na coleção organizada por Kristeva. E ela se torna indispensável porque traduz em palavras a atmosfera sinestésica das florações pintadas por O'Keeffe. Na leitura da obra colettiana, surgem imagens nas quais a faculdade de gosto se sobressai, fazendo-nos retornar às florações o'keeffianas pelo efeito sinestésico, por exemplo: "O olhar come a rosa, a vista se tornou um gosto, eu saboreio a flor como um confeito"43.

$\mathrm{Na}$ esteira dos caminhos semiotizáveis de nossa língua, não podemos nos esquecer de traçar a aproximação inevitável com a força protagonal de Água viva, de Clarice Lispector. Essa pintora-narradora, sensível à descrição das mais variadas flores, não se cansa de marcar o sentido do gosto em seus agônicos instantes de narração cuja fluidez está sempre a nos incitar ao chamado de uma escrita, ou de uma vida-escrita, que se faz no esgarçamento do tempo. O exemplo de uma rosa, que se prolonga na descrição do instante-já, levando várias linhas escritas para

\footnotetext{
40 "La vision du peintre est une naissance continuée” (MERLEAU-PONTY. L'Oeil et l'esprit, p. 32, tradução minha).

${ }^{41}$ MERLEAU-PONTY. L'Oeil et l'esprit, p. 16.

${ }^{42}$ MERLEAU-PONTY. L'Oeil et l'esprit, p. 16.

43 "Le regard mange la rose, la vue est devenue un goût, je savoure la fleur comme une confiture" (KRISTEVA. Le Génie féminin; la vie, la folie, les mots, tome III, p. 136).
} 
ter a sua morte narrada e mais tempo do que usualmente uma rosa comum leva para morrer, faz renascer, em palavra-escrita por uma narradorapintora, a sensação outrora pintada nas flores de O'Keeffe, nas quais se perde o todo e se elege alguma mancha pintada para a contemplação. Eis o recorte:

Sei da história de uma rosa. Parece-te estranho falar em rosa quando estou me ocupando com bichos? Mas ela agiu de um modo tal que lembra os mistérios animais. E dois em dois dias eu comparava uma rosa e colocava-a na água dentro da jarra feita especialmente estreita para abrigar o longo talo de uma só flor. De dois em dois dias a rosa murchava e eu a trocava por outra. Cor-de-rosa sem corante ou enxerto, porém do mais vivo rosa pela natureza mesmo. Sua beleza alargava o coração em amplidões. Parecia tão orgulhosa da turgidez de sua corola toda aberta e das próprias pétalas que era com uma altivez que se mantinha quase ereta. Porque não ficava totalmente ereta: com graciosidade inclinava-se sobre o talo que era fino e quebradiço. Uma relação íntima estabeleceu-se entre mim e a flor: eu a admirava e ela parecia sentir-se admirada. E tão gloriosa ficou na sua assombração e com tanto amor era observada que se passavam os dias e ela não murchava: continuava de corola toda aberta e túmida, fresca como flor nascida. Durou em beleza e vida uma semana inteira. Só então começou a dar mostras de algum cansaço. Depois morreu. Foi com relutância que a troquei por outra. ${ }^{44}$

Questão de gosto? Possivelmente, mas não do gosto instituído pela cultura falogocêntrica. Trata-se de começar a pensar nas possíveis escolhas ao alcance de nossas mãos, em suas coreografias singulares, como aquelas da foto de O'Keeffe. E, nesse percurso, que foi o de Artemísia e o de O'Keeffe, não são poucos os instantes fluidos que nos levam a buscar um campo de gosto próprio, muitas vezes soterrado por camadas há longos séculos modeladas pelos imperativos de transparência, presença, clareza e objetividade, muito bem disseminados pela metafísica da presença. Em Água viva, a pintora-narradora confessa

${ }^{44}$ LISPECTOR. Água viva, p. 59-60. 
o que foi percebido por Kristeva nas telas e cartas o'keeffianas: “Gosto de intensidades" ${ }^{45}$.

Nesse convite a escritas por vir de um feminino que se encontra como a "matéria vivida" a ser escrita por qualquer um, mas principalmente pelas mulheres, a inspeção dos traços dessas pintoras, misturados ao uso da cor, se insurge no cruzamento ético e estético da carne do mundo.

\section{Referências}

BENKE, Britta. Visiones del desierto. In: . Georgia O'Keeffe (1887-1986): flores en el desierto. Madrid: Taschen, 2003. p. 55-72.

DERRIDA, Jacques. Com o desígnio, o desenho. In: . Pensar em não ver: escritos sobre as artes do visível (1979-2004). Organização de Ginette Michaud, Joana Masó, Javier Bassas. Tradução de Marcelo Jacques de Moraes. Florianópolis: Ed. da UFSC, 2012. p 161-190.

GARRARD, Mary D. Artemisia Gentileschi: The Image of the Female Hero in Italian Baroque Art. Princeton: Princeton University Press, 1989, p. 290 .

JARDIM, Luciana Abreu. O corpo atravessado pela técnica. In: . Clarice Lispector e Julia Kristeva: dois discursos sobre o corpo. Orientador: Maria Eunice Moreira. 2008. 565 f. Tese (Doutorado em Letras - Teoria da Literatura) - Faculdade de Letras, Pontifícia Universidade Católica do Rio Grande do Sul, Porto Alegre, 2008. p. 218-397.

KRISTEVA, Julia. As metamorfoses da "linguagem" na descoberta freudiana (Os modelos freudianos da linguagem). In: . Sentido e contra-senso da revolta: poderes e limites da psicanálise I. Tradução de Ana Maria Scherer. Rio de Janeiro: Rocco, 2000, p. 62-112

KRISTEVA, Julia. Décollations. In: . Visions Capitales (avec Liudvig Feïerbakh). Paris: Réunion des musées nationaux, 1998. p. 81100.

${ }^{45}$ LISPECTOR. Água viva, p. 71. 
KRISTEVA, Julia. Des madones aux nus: une représentation de la beauté féminine. In: . La Haine et le pardon: pouvoirs et limites de la psychanalyse. Paris: Fayard, 2005. v. III, p. 143-173.

KRISTEVA, Julia. Falar em psicanálise: os símbolos da carne e do retorno. In: Meu alfabeto: ensaios de literatura, cultura e psicanálise. Tradução de Adriana Zavaglia. São Paulo: Ed. Sesc, 2017. p. 53-66.

KRISTEVA, Julia. La Forme inévitable. In: . La Haine et le pardon: pouvoirs et limits de la psychanalyse. Paris: Fayard, 2005. v. III, p. 481-500.

KRISTEVA, Julia. La Joie de Giotto. In: . Polylogue. Paris: Seuil, 1977. p. 383-408.

KRISTEVA, Julia. La Révolte intime: pouvoirs et limites da psychanalyse. Paris: Fayard, 1997. v. II.

KRISTEVA, Julia. La Révolution du langage poétique: l'avant-garde à la fin du XIX siècle. Lautréamont et Mallarmé. Paris: Seuil, 1974.

KRISTEVA, Julia. Le Génie féminin: la vie, la folie, les mots. Paris: Fayard, 2002. tome III: Colette.

KRISTEVA, Julia. Le Génie féminin: la vie, la folie, les mots. Paris: Fayard, 2000. tome II: Melanie Klein

KRISTEVA, Julia. Les Métamorphoses du "language" dans la découverte freudienne (Les modèles freudiens du language). In: Sens et nonsens de la révolte: pouvoirs et limites de la psychanalyse. Paris: Fayard, 1996. v. I, p. 51-102.

KRISTEVA, Julia. Possessions. Paris: Fayard, 1996.

KRISTEVA, Julia. Possessões. Tradução de Maria Helena Franco Martins. Rio de Janeiro: Rocco, 2003.

KRISTEVA, Julia. Pouvoirs de l'horreur. essais sur l'abjection. Paris: Seuil, 1980.

LISPECTOR, Clarice. Água viva. São Paulo: Círculo do livro, 1973.

MERLEAU-PONTY, Maurice. A linguagem indireta e as vozes do silêncio. In: . Textos escolhidos. Tradução e notas de Marilena de 
Souza Chaúi, Nelson Alfredo Aguilar, Pedro de Souza Moraes. 2 ed. São Paulo: Abril Cultural, 1984. p. 141-175.

MERLEAU-PONTY, Maurice. L'Oeil et l'esprit. Paris: Éd. Gallimard, 1964.

SHEPHERDSON, Charles. Uma libra de carne: a leitura lacaniana d' $O$ visível e o invisível. Tradução de Ronaldo Manzi Filho. Discurso. São Paulo, n. 36, p. 95-126, 2007. DOI: https://doi.org/10.11606/issn.23188863.discurso.2007.38074. 